ISSN: 1858-4837; E-ISSN: 2598-019X

Volume 15, Nomor 2 (2020),

https://jurnal.uns.ac.id/region

DOI: $10.20961 /$ region.v15i2.24440

\title{
Karakteristik pedagang kaki lima dan preferensinya terhadap lokasi kawasan Solo Techno Park
}

\author{
Characteristics of street vendors and their preference for locations in the Solo \\ Techno Park area
}

\author{
E A L Perdana ${ }^{1}$, P Rahayu ${ }^{1}$, and A Hardiana ${ }^{2}$ \\ ${ }^{1}$ Program Studi Perencanaan Wilayah dan Kota, Fakultas Teknik, Universitas Sebelas \\ Maret \\ ${ }^{2}$ Program Studi Arsitektur, Fakultas Teknik, Universitas Sebelas Maret
}

Corresponding author's email: eldora@ft.uns.ac.id

\begin{abstract}
Abstrak. Jalan Ki Hajar Dewantara merupakan salah satu ruas jalan yang termasuk dalam program penataan pemerintah untuk merelokasi PKL ke Pasar Panggungrejo pada tahun 2009. Sebagai tempat menyelenggarakan usaha informal, Jalan Ki Hajar Dewantara memiliki daya tarik yang tinggi karena lokasi yang berdekatan dengan berbagai pusat aktivitas, antara lain Solo Techno Park, kampus UNS Kentingan, kampus ISI Surakarta, Kantor BPN/ATR Kota Surakarta, Kantor Kecamatan Jebres, Balai Diklat Industri, dan Taman Cerdas. Meskipun sudah pernah dilakukan penataan, pada saat ini PKL masih bisa ditemui dengan mudah di ruas jalan tersebut. Penelitian ini bertujuan untuk mengetahui preferensi PKL terhadap karakteristik lokasi di Kawasan Solo Techno Park, yang terletak di Jalan Ki Hajar Dewantara. Penelitian juga menguraikan hubungan kesesuaian karakteristik PKL dengan karakteristik lokasi kawasan, yang juga mendukung preferensi PKL dalam berlokasi. Metode yang digunakan untuk menganalisis dalam penelitian ini adalah deskriptif serta analisis data statistik deskriptif yang menggunakan teknik skala Likert dalam mengukur preferensi PKL terhadap setiap karakteristik lokasi di Kawasan Solo Techno Park. Hasil analisis menunjukkan preferensi PKL terhadap karakteristik lokasi di Kawasan Solo Techno Park secara urut dari yang paling disukai yaitu: (1) lokasi strategis; (2) luas ruang PKL; (3) pusat aktivitas; (4) aksesibilitas; (5) lalu lintas jalan; (6) sarana dan prasarana PKL, dan; (7) aglomerasi PKL.
\end{abstract}

Kata Kunci: Analisis Lokasi; Karakteristik Lokasi; PKL; Preferensi; Sektor Informal; Solo Techno Park 


\begin{abstract}
Ki Hajar Dewantara Street was one of the streets that were included in the government's program of street vendor relocation to Panggungrejo Market in 2009. As a place to conduct informal businesses, the Ki Hajar Dewantara Street is seen as very attractive considering there are many activity centers located along the street. Some notable activity centers include STP, UNS Kentingan, ISI Surakarta, BPN/ATR office of Surakarta, office of Kecamatan Jebres, Balai Diklat Industri, and Taman Cerdas. Despite the regulation that had been applied to the street vendors, many street vendors can still be easily found on the street. This research aims to determine street vendors' preferences of location characteristics in the area of Solo Techno Park (STP), which is situated on the Ki Hajar Dewantara Street. This research shows the compatibility between street vendors' characteristics and location characteristics in the area that contributes to the street vendors' preferences. The method used in the research is descriptive and descriptive statistics analysis which used Likert scale to measure street vendors' preferences towards each location characteristic. Based on the results, the street vendors' preferences of location characteristics in the area of STP sorted from the most preferred are: (1) the strategic location; (2) street vendors' size of space; (3) activity centers; (4) accessibility; (5) road traffic; (6) street vendors' facility and infrastructure, and; (7) street vendors' agglomeration.
\end{abstract}

Keywords: Informal Sector; Location Analysis; Location Characteristics; PKL; Preferences; Solo Techno Park

\title{
1. Pendahuluan
}

Tingginya pertumbuhan penduduk di perkotaan secara pesat adalah sebuah fenomena yang tak terhindarkan, salah satu penyebabnya adalah besarnya minat masyarakat untuk datang ke kota. Pertumbuhan penduduk di kota yang begitu pesat seringkali tidak diimbangi dengan perkembangan kesempatan kerja. Selain itu, sebagian tenaga kerja yang datang ke kota juga tidak memiliki keahlian atau modal untuk bisa bekerja di sektor formal. Maka terjadilah suatu fenomena dimana para tenaga kerja yang tidak dapat ditampung sektor formal berusaha mempertahankan kehidupannya di kota dengan masuk ke sektor informal. Salah satu subsektor informal yang banyak diminati dan sangat melekat dengan citra perkotaan di Indonesia adalah pedagang kaki lima (PKL).

Keterbatasan lapangan kerja dan kurangnya kemampuan tenaga kerja penduduk pendatang untuk bersaing dalam sektor formal memicu pertumbuhan PKL di perkotaan. Dikutip dari Rachbini D J dan Abdul H [1], mereka yang melibatkan diri di sektor informal pada dasarnya berkaitan dengan etos kewirausahaan (enterpreneurship) yang mereka miliki. Hal ini tentu dapat dilihat sebagai dampak yang positif, karena dengan masuknya tenaga kerja tersebut ke sektor informal maka angka pengangguran di kota ikut menurun. Namun disamping itu PKL juga membawa dampak negatif, salah satunya karena sifatnya yang fleksibel dalam hal waktu dan tempat, maka seringkali lokasi yang dipilih PKL tidak legal atau diperbolehkan untuk kegiatan perdagangan. Hal ini tentu saja dianggap sebagai pelanggaran terhadap aturan tata ruang, yang mana dapat mengganggu estetika kawasan, menimbulkan kesan kumuh serta menghambat alur pergerakan transportasi di sekitar kawasan. 
Bermula dari isu ini, Pemerintah Kota Surakarta menetapkan sebuah kebijakan yaitu Zero Growth for PKL dengan tujuan untuk menekan pertumbuhan PKL non formal hingga 0\%. Didukung dengan Peraturan Daerah Kota Surakarta No. 3 Tahun 2008 tentang Pengelolaan PKL [2], pemerintah kota terus berupaya menekan jumlah PKL melalui berbagai bentuk penataan dengan membuat sentra-sentra PKL, yang dapat mengubah status PKL dari informal atau ilegal menjadi formal atau legal. Menurut Mc Gee and Yeung [3], tindakan penanganan PKL atau disebut juga dengan hawkers dapat dilakukan dengan beberapa hal, yakni stabilisasi, relokasi dan pemindahan.

Salah satu bentuk penanganan yang diterapkan di kota Surakarta adalah dengan cara relokasi. Contohnya adalah relokasi PKL di Pasar Panggungrejo, Kelurahan Jebres, Kecamatan Jebres, Kota Surakarta. Pasar Panggungrejo adalah pasar yang dibangun khusus untuk mengakomodasi PKL yang di relokasi dari Jalan Ki Hajar Dewantara. Namun setelah lokasinya dipindahkan, para pedagang mengeluhkan minimnya konsumen yang datang dan sebagian dari pedagang terpaksa harus berhenti berjualan karena kehilangan pembelinya. Kondisi Pasar Panggungrejo saat ini sepi pengunjung dan mulai ditinggalkan PKL yang direlokasi ke pasar.

Meskipun sudah pernah dilakukan penanganan relokasi, masih dapat dengan mudah ditemui berbagai jenis PKL yang beraktivitas di Jalan Ki Hajar Dewantara. Salah satu titik di Jalan Ki Hajar Dewantara yang dapat dengan mudah kita temui PKL harian dengan jumlah yang cukup banyak adalah Kawasan Solo Techno Park. Titik ini memiliki karakteristik tersendiri dibanding dengan titik-titik PKL lainnya di Jalan Ki Hajar Dewantara, karena banyaknya PKL yang berdagang di sepanjang jalan dan menghidupkan pola aktivitas di kawasan tersebut, terutama pada pagi dan malam hari. Pada siang hari, PKL juga berjualan secara ilegal (diluar waktu yang ditentukan pemerintah, yakni pukul 17.00 hingga 05.00) sehingga menimbulkan kesan tidak tertib dan menurunkan keindahan citra kawasan. Fenomena yang telah diuraikan di atas menjadi latar belakang peneliti untuk melakukan sebuah penelitian yang bertujuan untuk mengetahui hubungan kesesuaian karakteristik PKL dengan karakteristik lokasi kawasan, yang juga mendukung preferensi PKL dalam berlokasi di Kawasan Solo Techno Park.

\section{Metode}

Jenis penelitian digolongkan sebagai penelitian konfirmatori dengan metode deskriptif serta analisis data statistik deskriptif yang menggunakan teknik skala Likert dalam mengukur preferensi PKL terhadap setiap karakteristik lokasi di Kawasan Solo Techno Park. Ruang lingkup wilayah dalam penelitian ini adalah ruas Jalan Ki Hajar Dewantoro dari gerbang belakang ISI Surakarta hingga ruas jalan arah ke Taman Cerdas. Ruas jalan PKL memiliki panjang 442 meter. Hal yang paling mendasari batasan lokasi ini adalah ruas jalan yang terpilih merupakan ruas jalan yang banyak menarik PKL terutama pada malam hari, mengaktifkan kembali pola aktivitas di kawasan tersebut. Berikut Gambar 1 adalah peta lokasi studi dan penyebaran PKL berdasarkan waktu pelayanan 

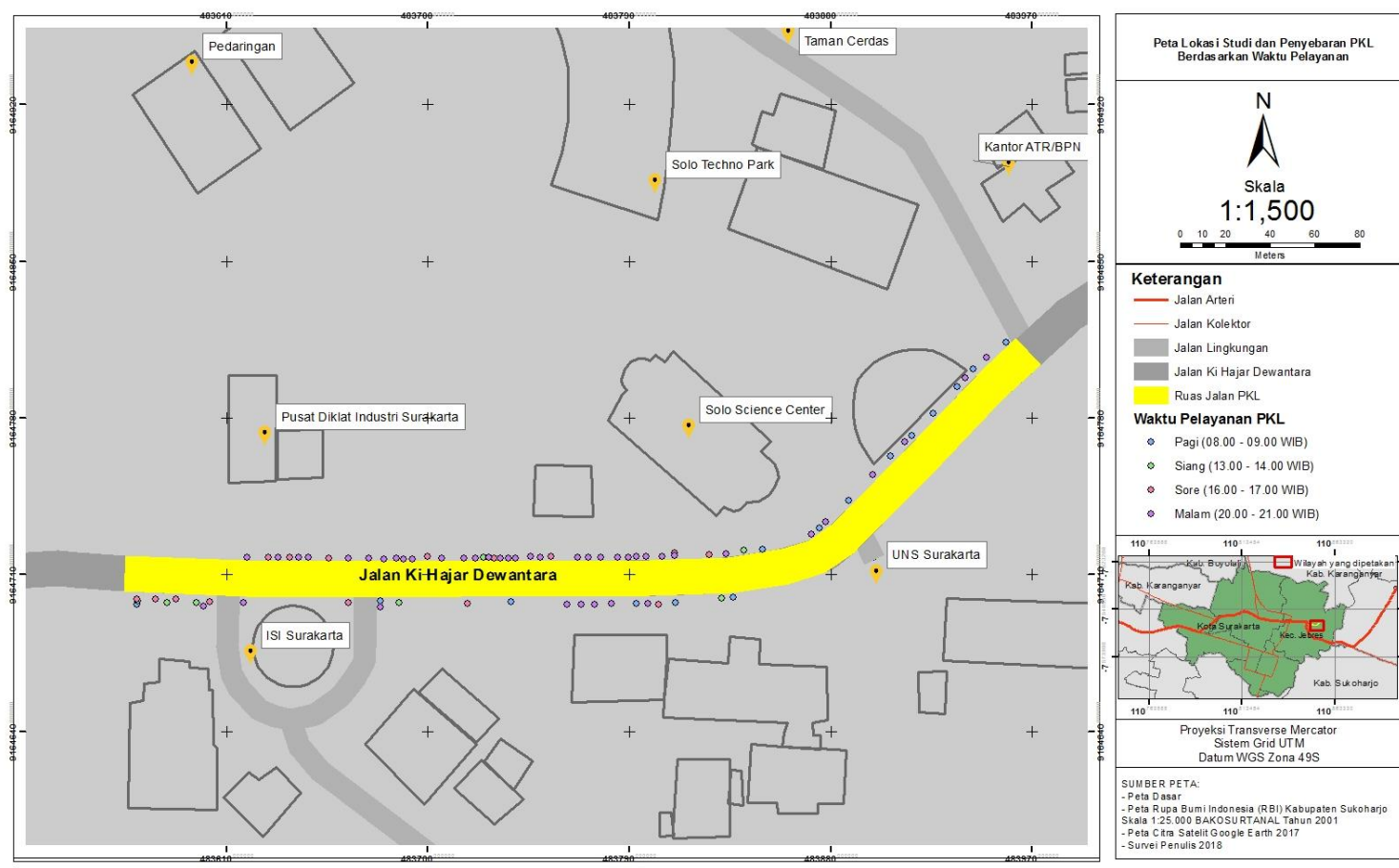

Gambar 1. Ruang lingkup penelitian.

Penelitian ini menggunakan populasi PKL dan sampel pengunjung dalam penghimpunan data. Populasi jumlah pedagang PKL relatif tidak banyak yaitu sejumlah 65 pedagang, sehingga tidak dilakukan pengambilan sampel dan langsung menggunakan populasinya (sampling jenuh). Sebagai gambaran populasi PKL yang menjadi responden penelitian, berikut Tabel 1 adalah statistik PKL di Kawasan Solo Techno Park berdasarkan jenis dagangan.

Tabel 1. Populasi PKL berdasarkan jenis dagangan.

\begin{tabular}{lr}
\hline \multicolumn{2}{c}{ Jenis Dagangan } \\
\hline Makanan Siap Saji Di Tempat & 27 \\
Makanan Siap Saji Di Bawa Pulang & 34 \\
Non Makanan & 1 \\
Jasa & 3 \\
Total & 65 \\
\hline
\end{tabular}

Sedangkan untuk pengambilan sampel jumlah pengunjung digolongkan pada populasi undefined karena jumlahnya tidak terhingga, yang sampelnya ditentukan melalui perhitungan dengan rumus statistik sebagai berikut:

$$
\mathrm{N}=\left(\frac{Z \alpha / 2 \cdot \sigma}{e^{2}}\right)^{2}
$$


Dalam penentuan dan pengambilan sampel ditemukan bahwa jumlah responden adalah sejumlah 97 responden. Untuk penelitian ini jumlah tersebut dibulatkan 100 responden (sampling kuota) untuk mempermudah pengolahan data.

Teknik pengumpulan data yang digunakan dalam penelitian ini ada tiga, yakni observasi, kuesioner, dan dokumentasi. Teknik observasi, wawancara dan studi literatur digunakan untuk menguraikan karakteristik lokasi Kawasan Solo Techno Park sebagai tempat berlokasi PKL, sedangkan kuesioner digunakan sebagai input skala Likert dan mengetahui preferensi PKL terhadap Kawasan Solo Techno Park sebagai lokasi PKL.

Data dalam analisis penelitian ini dihimpun melalui survei kuesioner dan wawancara kepada 65 PKL yang ditemui pada waktu pagi, siang, sore dan malam. PKL diminta untuk memberi nilai pada tujuh set penyataan untuk mengetahui preferensi PKL tentang 7 variabel karakteristik kawasan yang sudah di observasi sebelumnya dengan metode skoring. Skoring tersebut dirumuskan melalui teknik skala Likert, yakni skala yang digunakan untuk mengukur sikap, pendapat dan persepsi seseorang atau sekelompok tentang kejadian atau gejala sosial (yang selanjutnya disebut sebagai variabel penelitian) [4]. Dalam pelaksanaannya, 65 PKL tersebut akan ditanya mengenai preferensinya terhadap 7 karakteristik PKL, melalui skoring 14 butir pernyataan serta menjawab 7 butir pertanyaan terbuka atau open questions.

Untuk menguji validitas dan reliabilitas instrumen, peneliti menggunakan analisis dengan SPSS. Untuk tingkat validitas dilakukan uji signifikansi dengan membandingkan nilai $r$ hitung dengan nilai $r$ tabel. Untuk uji reliabilitas dilakukan dengan metode koefisien Cronbach Alpha $(\alpha)$ dengan menghitung rata-rata interkorelasi diantara butir-butir pernyataan dalam kuesioner. Seluruh kuesioner yang dihimpun dari 65 responden PKL kemudian ditabulasi dan dihitung skornya pada masing-masing bobot dengan rumus $\mathrm{T} \times \mathrm{Pn}$, dengan $\mathrm{T}$ merupakan jumlah responden yang memilih skor Likert dan Pn merupakan bobot angka skor Likert, sehingga didapatkan total skor. Agar mendapatkan hasil interpretasi, terlebih dahulu harus diketahui skor tertinggi $(X)$ dan skor terendah $(Y)$ untuk item penilaian dengan rumus $Y=$ skor tertinggi Likert $\mathrm{x}$ jumlah responden dan $\mathrm{X}=$ skor terendah Likert $\mathrm{x}$ jumlah responden. Penilaian interpretasi responden terhadap setiap variabel adalah hasil nilai yang dihasilkan dengan menggunakan rumus Index $\%=$ Total Skor / Y x 100. Untuk mengetahui interval (rentang jarak) dan kriteria interpretasi skor digunakan metode interval skor persen (I) dengan rumus I = 100 / Jumlah Skor (Likert).

\section{Hasil penelitian dan pembahasan}

Konsep preferensi berkaitan dengan kemampuan dalam menyusun prioritas pilihan agar dapat mengambil keputusan [5]. Minimalnya ada dua sikap yang berkaitan dengan preferensi konsumen yaitu lebih suka (prefer) dan atau sama-sama disukai (indifference). Penelitian ini bertujuan untuk mengetahui preferensi PKL terhadap karakteristik lokasi di Kawasan Solo Techno Park, yang terletak di Jalan Ki Hajar Dewantara. Variabel karakteristik lokasi yang digunakan dalam penelitian ini diambil dari hasil sintesis dari berbagai penelitian terdahulu mengenai karakteristik PKL, terutama ditinjau dari bagaimana persepsi PKL terhadap sebuah lokasi sehingga tercipta ketertarikan/preferensi untuk melakukan aktivitas 
ekonomi informal di lokasi tersebut. Adapun perumusan variabel dan indikator dari karakteristik lokasi PKL disajikan dalam Tabel 2 berikut.

Tabel 2. Variabel dan indikator penelitian.

\begin{tabular}{|c|c|c|c|c|}
\hline Aspek & Variabel & $\begin{array}{c}\text { Definisi } \\
\text { Operasional }\end{array}$ & Indikator & Sumber \\
\hline \multirow{7}{*}{$\begin{array}{c}\text { Karakteristik } \\
\text { Lokasi PKL }\end{array}$} & Aglomerasi PKL & $\begin{array}{l}\text { Jenis PKL yang } \\
\text { berkumpul di } \\
\text { kawasan studi }\end{array}$ & $\begin{array}{c}\text { Pemetaan } \\
\text { berdasarkan jam } \\
\text { buka dan jenis } \\
\text { PKL }\end{array}$ & [6-8] \\
\hline & $\begin{array}{c}\text { Lokasi strategis } \\
\text { PKL }\end{array}$ & $\begin{array}{l}\text { Tingkat strategis } \\
\text { kawasan ditinjau } \\
\text { dari segi } \\
\text { keruangan }\end{array}$ & $\begin{array}{l}\text { Visibilitas lokasi } \\
\text { diukur dari } \\
\text { keuntungan PKL } \\
\text { dan jarak } \\
\text { dengan tempat } \\
\text { tinggal }\end{array}$ & [6-12] \\
\hline & $\begin{array}{c}\text { Sarana } \\
\text { Prasarana PKL }\end{array}$ & $\begin{array}{l}\text { Infrastruktur yang } \\
\text { mendukung } \\
\text { kegiatan PKL }\end{array}$ & $\begin{array}{c}\text { Identifikasi } \\
\text { sarana dan } \\
\text { prasarana yang } \\
\text { digunakan PKL }\end{array}$ & {$[6-8,13]$} \\
\hline & Aksesibilitas PKL & $\begin{array}{c}\text { Kemudahan akses } \\
\text { lokasi }\end{array}$ & $\begin{array}{l}\text { Akses lokasi } \\
\text { ditinjau dari } \\
\text { jaringan } \\
\text { transportasi } \\
\text { kota maupun } \\
\text { regional }\end{array}$ & {$[6,8-10,12]$} \\
\hline & Luas Ruang PKLf & $\begin{array}{l}\text { Ukuran kawasan } \\
\text { ditinjau dari segi } \\
\text { keruangan }\end{array}$ & $\begin{array}{c}\text { Identifikasi } \\
\text { besar area yang } \\
\text { digunakan PKL } \\
\text { dalam } \\
\text { beraktivitas }\end{array}$ & {$[6,10,12]$} \\
\hline & Lalu Lintas Jalan & $\begin{array}{l}\text { Daya tarik dilihat } \\
\text { dari kepadatan } \\
\text { lalu lintas }\end{array}$ & $\begin{array}{l}\text { Identifikasi } \\
\text { tingkat } \\
\text { keramaian dan } \\
\text { kepadatan jalan }\end{array}$ & [10] \\
\hline & Pusat Aktivitas & $\begin{array}{l}\text { Daya tarik dilihat } \\
\text { dari kegiatan yang } \\
\text { terjadi di kawasan }\end{array}$ & $\begin{array}{l}\text { Identifikasi } \\
\text { penggunaan } \\
\text { lahan di sekitar } \\
\text { kawasan }\end{array}$ & {$[6-9,13]$} \\
\hline
\end{tabular}

3.1 Kesesuaian karakteristik pkl terhadap karakteristik lokasi kawasan Solo Techno Park Karakteristik yang dimiliki PKL menjadi pertimbangan PKL dalam menentukan lokasi yang cocok untuk melakukan aktivitas perdagangan. Menurut McGee dan Yeung [3], terdapat 
enam penggolongan karakteristik PKL, yakni jenis komoditas, skala pelayanan, lokasi asal $\mathrm{PKL}$, pola penyebaran, sifat pelayanan dan waktu pelayanan.

3.1.1 Jenis Komoditas. Menurut Rahayu [14], jenis dagangan yang ditawarkan oleh PKL dapat dikelompokkan menjadi 5 (lima) kelompok utama, yaitu makanan mentah, makanan siap saji dibawa pulang, makanan siap saji ditempat, non makanan, serta jasa. Sedangkan menurut Mc Gee dan Yeung [3], jenis dagangan yang ditawarkan oleh PKL dapat dikelompokkan menjadi 4 (empat) kelompok utama, yakni makanan yang belum diproses, makanan siap saji, barang dan jasa. Berdasarkan teori tersebut, PKL yang berada di Kawasan Solo Techno Park dapat digolongkan dalam tiga kelompok utama jenis komoditas, antara lain makanan siap saji (ditempat dan dibawa pulang), non makanan atau barang dan jasa. Hal ini sesuai dengan Kawasan Solo Techno Park di kelilingi berbagai pusat aktivitas mulai dari aktivitas pendidikan, perkantoran maupun perdagangan, sehingga sesuai dengan karakteristik PKL yang menyediakan kebutuhan sehari-hari seperti makanan siap saji, barang serta jasa.

3.1.2 Skala pelayanan. Rahayu [15] menyatakan bahwa lokasi asal konsumen akan berpengaruh terhadap skala operasi layanan PKL. Skala pelayanan PKL di dapat dikatakan besar jika setidaknya terdapat pengunjung yang menempuh setidaknya $3 \mathrm{~km}$ dari lokasi aktivitas utama mereka (Hanarti dalam Haryanti, [16]). Dari 100 orang pengunjung, lokasi terjauh pengunjung yang datang ke Kawasan Solo Techno Park adalah dari SMAN 4 Surakarta yang berjarak sekitar $6.6 \mathrm{Km}$ dari kawasan dengan rata-rata jarak asal seluruh pengunjung sebesar $1.5 \mathrm{Km}$. Sehingga, skala pelayanan PKL di Kawasan Solo Techno Park tergolong besar. Besarnya skala pelayanan PKL di Kawasan Solo Techno Park dipengaruhi oleh karakteristik lokasi kawasan yakni terdapat beragam pusat aktivitas yang berada di jalan arteri primer. Hal ini menjadikan kawasan sangat aksesibel baik bagi pengunjung maupun pedagang.

3.1.3 Lokasi asal PKL. Menurut McGee dan Yeung [3] PKL dapat diukur melalui empat hal, yakni lokasi rumah PKL, jarak rumah ke lokasi berjualan, waktu yang ditempuh untuk sampai ke lokasi berjualan, dan jenis transportasi yang digunakan untuk berangkat dari rumah ke lokasi berjualan. Budi [12] menyebutkan bahwa jarak lokasi usaha dengan tempat tinggal PKL cenderung dekat. Hal ini kurang sesuai dengan data di lokasi studi yang menunjukkan bahwa PKL yang berjualan di kawasan Solo Techno Park datang dari dalam Kota Surakarta maupun luar Kota Surakarta. Lokasi rumah PKL terjauh adalah di Kecamatan Tawangsari Kabupaten Sukoharjo, dengan jarak rumah terjauh adalah sekitar $25 \mathrm{Km}$ dari kawasan, dengan rata-rata jarak tempat tinggal PKL keseluruhan adalah $4.4 \mathrm{Km}$, dan waktu paling lama ditempuh adalah 40 menit serta jenis transportasi yang paling banyak digunakan PKL adalah sepeda motor. Kawasan Solo Techno Park dianggap menarik bagi PKL yang berasal dari luar Kota Surakarta karena karakteristik lokasinya yang dianggap strategis, sehingga jarak yang ditempuh dianggap sebanding dengan keuntungan yang didapatkan ketika berjualan di lokasi.

3.1.4 Pola penyebaran. Berdasarkan pola penyebarannya, aktivitas PKL menurut Mc. Gee dan Yeung [3] dapat dikelompokkan dalam 2 (dua) pola, yaitu pola penyebaran 
mengelompok (Focus Aglomeration) dan Pola Penyebaran Memanjang (Linier Concentration). Pola penyebaran aktivitas PKL di Kawasan Solo Techno Park adalah memanjang secara linier mengikuti ruas jalan. Pola penyebaran seperti ini biasanya dipengaruhi oleh adanya pertimbangan aglomerasi, yaitu suatu pemusatan atau pengelompokkan pedagang sejenis atau pedagang yang mempunyai sifat komoditas yang sama atau saling menunjang, dan biasanya dijumpai pada para pedagang makanan dan minuman [12]. Pendapat ini juga didukung oleh Widjajanti [17] yang menyatakan bahwa pola penyebaran PKL dalam berdagang biasanya berbentuk aglomerasi yang terdiri dari beberapa kelompok jenis dagangan, agar dapat saling mendukung antar jenis dagangan yang saling terkait dan adanya pola aglomerasi ini memudahkan pengunjung untuk memilih jenis dagangan. Pola kegiatan linier lebih banyak dipengaruhi oleh pertimbangan aksesibilitas yang tinggi pada lokasi yang bersangkutan. Hal ini sangat menguntungkan bagi pedagang sebab dengan menempati lokasi yang beraksesibilitas tinggi akan mempunyai kesempatan yang lebih besar dalam meraih konsumen, sesuai dengan karakteristik lokasi Kawasan Solo Techno Park yang memiliki aksesibilitas yang tinggi karena berada di jalan lokal primer yakni Jalan Ki Hajar Dewantara.

3.1.5 Sifat pelayanan. Berdasarkan sifat pelayanannya, PKL menurut Mc. Gee dan Yeung [3] dapat dikelompokkan menjadi 3 (tiga), yaitu pedagang menetap (static), pedagang semi menetap (semi static) dan pedagang keliling (mobile). Berdasarkan sifat pelayanannya, hampir seluruh PKL di Kawasan Solo Techno Park memiliki sifat pelayanan statis atau menetap, yakni suatu bentuk layanan yang sifatnya menetap pada suatu lokasi tertentu. Widjajanti [17] menyebutkan bahwa PKL dalam beraktivitas seringkali bersifat menetap, karena dengan menetap dapat memiliki pelanggan tetap, lokasi berdagang tetap, dan tempat berdagang yang pasti, sehingga PKL tidak perlu berjualan berkeliling mencari pembeli. Di Kawasan Solo Techno Park terdapat beberapa PKL static yang menggunakan sarana gerobak, sehingga lebih praktis untuk dititipkan di lokasi maupun dibawa pulang beserta sarana lainnya seperti tikar, alat masak dan lain sebagainya. Karakteristik lokasi Kawasan Solo Techno Park yang memiliki bahu dan trotoar jalan yang cukup luas dianggap mencukupi PKL dalam mengakomodasi sarana dan prasarana yang digunakan, sehingga sesuai dengan karakteristik PKL.

3.1.6 Waktu pelayanan. Kawasan Solo Techno Park berada di Jalan Ki Hajar Dewantara, yang telah diatur penggunaan ruangnya untuk sektor informal dalam Peraturan Walikota Surakarta No. 17-B Tahun 2012 [2], bahwa lokasi usaha PKL adalah tepi-tepi jalan Kota Surakarta yang tidak mengakibatkan terganggunya fungsi jalan dengan ketentuan waktu usaha mulai pukul 17.00 sampai dengan 05.00 WIB. PKL di Kawasan Solo Techno Park dapat ditemukan di setiap waktu pagi, siang, sore, maupun malam hari, sesuai dengan Mc Gee dan Yeung [3] bahwa pola aktivitas PKL menyesuaikan terhadap irama dari ciri kehidupan masyarakat sehari-hari. Hal ini juga didukung oleh Widjajanti [17] yang menyatakan bahwa waktu berdagang PKL mengikuti aktivitas utama yang ada di kawasan, yaitu dapat mengikuti waktu aktivitas perdagangan, olah raga, rekreasi/hiburan, dengan memanfaatkan akumulasi pengunjung yang datang melaksanakan aktivitas - aktivitas yang ada di kawasan. Kawasan 
Solo Techno Park merupakan kawasan yang selalu hidup karena dekat dengan permukiman mahasiswa dan masyarakat, sesuai dengan karakteristik PKL yang fleksibel dalam hal jam buka maupun tutup.

\subsection{Preferensi PKL terhadap karakteristik lokasi kawasan Solo Techno Park}

Hasil analisis deskriptif statistik menggunakan skala Likert pada Tabel 3 dan Tabel 4 menunjukkan bahwa preferensi PKL terhadap karakteristik lokasi di Kawasan Solo Techno Park secara urut dari yang paling disukai adalah lokasi strategis, luas ruang PKL, pusat aktivitas, aksesibilitas, lalu lintas jalan, sarana dan prasarana PKL, dan aglomerasi PKL. Pembahasan selengkapnya mengenai penghimpunan dan pengolahan data, konsep pembobotan serta perhitungan ranking terdapat di subbab metode penelitian.

Tabel 3. Hasil kuesioner keseluruhan.

\begin{tabular}{|c|c|c|c|c|c|c|c|c|c|c|c|c|c|c|}
\hline \multirow[t]{2}{*}{ Bobot } & \multicolumn{2}{|c|}{$\begin{array}{c}\text { Aglomerasi } \\
\text { PKL }\end{array}$} & \multicolumn{2}{|c|}{$\begin{array}{c}\text { Lokasi } \\
\text { Strategis }\end{array}$} & \multicolumn{2}{|c|}{$\begin{array}{c}\text { Sarana } \\
\text { dan } \\
\text { Prasarana } \\
\text { PKL }\end{array}$} & \multicolumn{2}{|c|}{ Aksesibilitas } & \multicolumn{2}{|c|}{$\begin{array}{c}\text { Luas Ruang } \\
\text { PKL }\end{array}$} & \multicolumn{2}{|c|}{$\begin{array}{c}\text { Lalu Lintas } \\
\text { Jalan }\end{array}$} & \multicolumn{2}{|c|}{$\begin{array}{c}\text { Pusat } \\
\text { Aktivitas }\end{array}$} \\
\hline & ag1 & ag2 & ls1 & ls2 & sp1 & sp2 & ak1 & ak2 & lr1 & lr2 & 111 & 112 & pa1 & pa2 \\
\hline 5 poin & 80 & 80 & 100 & 195 & 160 & 45 & 100 & 130 & 110 & 155 & 105 & 110 & 135 & 80 \\
\hline 4 poin & 152 & 144 & 148 & 52 & 76 & 168 & 112 & 132 & 136 & 112 & 136 & 112 & 112 & 164 \\
\hline 3 poin & 24 & 21 & 24 & 39 & 42 & 27 & 51 & 0 & 24 & 3 & 21 & 30 & 24 & 12 \\
\hline 2 poin & 6 & 12 & 0 & 0 & 0 & 10 & 0 & 12 & 2 & 8 & 6 & 10 & 4 & 8 \\
\hline 1 poin & 0 & 0 & 0 & 0 & 0 & 0 & 0 & 0 & 0 & 1 & 0 & 0 & 0 & 0 \\
\hline Total Skor & 262 & 257 & 272 & 286 & 278 & 250 & 263 & 274 & 272 & 279 & 268 & 262 & 275 & 264 \\
\hline Mean & \multicolumn{2}{|c|}{390,5} & \multicolumn{2}{|c|}{415} & \multicolumn{2}{|c|}{403} & \multicolumn{2}{|c|}{400} & \multicolumn{2}{|c|}{411,5} & \multicolumn{2}{|c|}{399} & \multicolumn{2}{|c|}{407} \\
\hline Indeks \% & \multicolumn{2}{|c|}{79,85} & \multicolumn{2}{|c|}{85,85} & \multicolumn{2}{|c|}{81,23} & \multicolumn{2}{|c|}{82,62} & \multicolumn{2}{|c|}{84,77} & \multicolumn{2}{|c|}{81,54} & \multicolumn{2}{|c|}{82,92} \\
\hline
\end{tabular}

Tabel 4. Urutan variabel PKL.

\begin{tabular}{lcc}
\hline & Preferensi PKL & Index $\%$ \\
\hline 1 & Lokasi Strategis & 85,85 \\
2 & Luas Ruang PKL & 84,77 \\
3 & Pusat Aktivitas & 82,92 \\
4 & Aksesibilitas & 82,62 \\
5 & Lalu Lintas Jalan & 81,54 \\
6 & Sarana dan Prasarana PKL & 81,23 \\
7 & Aglomerasi PKL & 79,85 \\
\hline
\end{tabular}

3.2.1 Preferensi PKL terhadap lokasi strategis. Berdasarkan hasil analisis preferensi PKL, lokasi strategis menempati urutan pertama dari tujuh karakteristik yang paling dipertimbangkan PKL dalam memilih lokasi berdagang. Dikutip dari penelitian Maulidiyah dan Idajati [6], salah satu ciri lokasi berdagang yang strategis meliputi visibilitas. Lokasi strategis PKL yang memiliki tingkat visibilitas yang tinggi berkaitan erat dengan pendapatan 
pedagang. Hasil survei wawancara dengan PKL menunjukkan bahwa pendapatan kotor per bulan rata-rata PKL di Kawasan Solo Techno Park adalah sebesar Rp. 4.000.000, dengan PKL yang memiliki keuntungan kotor tertinggi adalah sebesar Rp. 27.000.000 per bulan (PKL makanan siap saji, jenis komoditas Bakmi Jawa), dan pendapatan kotor terendah PKL adalah sebesar Rp. 600.000 per bulan (PKL makanan siap saji, jenis komoditas minuman dingin). Hal ini dianggap menjadi daya tarik tersendiri bagi PKL karena pedagang mendapatkan untung yang dianggap cukup besar meskipun modal usaha yang dikeluarkan tergolong sedikit.

Menurut Duwit [11], PKL mengganggap sebuah lokasi strategis jika lokasi tersebut dekat dengan keramaian serta tempat tinggal pedagang. Hal ini sesuai dengan kondisi di lapangan, karena Kawasan Solo Techno Park dikelilingi oleh berbagai pusat aktivitas pendidikan maupun perkantoran. Terutama bagi PKL makanan siap saji yang sebagian besar menempati lokasi kawasan Solo Techno Park, para pedagang cenderung memilih berlokasi mendekati fungsi perdagangan dan perkantoran, serta memilih mengelompok dalam berlokasi [13]. Selain dekat dengan keramaian dan visibilitas yang tinggi, lokasi yang strategis adalah lokasi yang dekat dengan tempat tinggal. Budi [12] menyatakan bahwa jarak lokasi usaha PKL dengan tempat tinggal cenderung dekat, sesuai dengan hasil analisis di lapangan bahwa sebagian besar PKL berasal dari dalam kota Solo yakni sebanyak 80\%, dengan persentase PKL yang tinggal di Kecamatan Jebres adalah sebesar 40\%. Terkait tingkat strategisnya lokasi ditinjau dari lokasi asal PKL, menurut Widodo [7] keterkaitan pemilihan lokasi ke tempat tinggal PKL diduga menyangkut barang dagangan dan alat-alat yang di bawa serta transportasi yang digunakan seperti penjelasan pada Tabel 5. Temuan di lokasi studi sesuai dengan teori tersebut, karena data yang telah dihimpun menunjukkan bahwa sebagian besar PKL yang berjualan menggunakan gerobak dan pikulan yang mudah untuk dibawa dari rumah.

Tabel 5. Hasil skoring variabel lokasi strategis.

\begin{tabular}{lllllll}
\hline \multicolumn{7}{c}{$\begin{array}{l}\text { Urutan 1 - Lokasi Strategis } \\
\text { (Indeks Persentase: 85,85\%) }\end{array}$} \\
\hline Kode & Item Pernyataan & STS & TS & N & S & SS \\
\hline Is1 & $\begin{array}{l}\text { Saya merasa banyak pengunjung } \\
\text { datang membeli karena lokasi saya } \\
\text { mudah dilihat orang yang berlalu- }\end{array}$ & $0 \%$ & $0 \%$ & $12,31 \%$ & $56,92 \%$ & $30,77 \%$ \\
& $\begin{array}{l}\text { lalang } \\
\text { Saya merasa tempat tinggal saya } \\
\text { dekat dengan lokasi Kawasan Solo } \\
\text { Is2 }\end{array}$ & & & & \\
& & & $20 \%$ & $20 \%$ & $60 \%$ \\
\hline
\end{tabular}

3.2.2 Preferensi PKL terhadap luas ruang PKL. Berdasarkan hasil analisis preferensi PKL, luas ruang $\mathrm{PKL}$ menempati urutan kedua dari tujuh karakteristik yang paling dipertimbangkan PKL dalam memilih lokasi berdagang. Dalam menyelenggarakan aktivitas jual beli, PKL di Kawasan Solo Techno Park memanfaatkan bahu jalan dan trotoar, sesuai dengan yang pernyataan Kadir [9] bahwa karakteristik penggunaan ruang yang digunakan PKL adalah badan jalan/trotoar, area hijau dan halaman rumah/tanah kosong milik warga 
masyarakat. Jalan Ki Hajar Dewantara digolongkan sebagai jalan lokal primer dan seperti jalan lokal primer di Indonesia pada umumnya, Jalan Ki Hajar Dewantara memiliki lebar jalan bersih sebesar 8 meter, dengan bahu jalan sebesar 2 meter dan trotoar sebesar 2 meter. Ruang kosong di bahu jalan dan trotoar yang cukup luas dianggap sangat memudahkan PKL untuk membangun tenda, menggelar tikar serta memarkirkan kendaraan. Menurut Maulidiyah dan Idajati [6], setiap pedagang PKL setidaknya memiliki luas tempat berdagang 2 meter persegi agar terlihat rapi tertata. PKL makanan siap saji ditempat cenderung menggunakan sarana dagang warung/tenda yang membutuhkan luas tempat berdagang yang lebih besar (lebih dari $3 \mathrm{~m} 2$ ) daripada PKL makanan siap saji yang dibawa pulang (kurang dari 3m2) [15]. Hal ini dibuktikan dengan hasil pengumpulan data di lapangan yang menunjukkan bahwa secara garis besar, PKL di Kawasan Solo Techno Park memiliki luas ruang yang berbeda-beda, dengan ukuran paling besar $3 \times 9$ meter (PKL HIK/Angkringan, sarana ditempat) dan paling kecil $2 \times 1$ meter (PKL Roti Bakar dan PKL Sol Sepatu, sarana dibawa pulang). Budi [12] berpendapat bahwa sarana dagang dan luas tempat yang dipergunakan oleh pedagang mempunyai hubungan yang cukup signifikan dan erat, hal ini juga terlihat dari keadaan luas ruang PKL di Kawasan Solo Techno Park yang menyesuaikan dengan kebutuhan masing-masing PKL.

Luas ruang PKL di Kawasan Solo Techno Park juga tergantung dari jumlah pembeli yang datang seperti yang tertera pada Tabel 6. Terutama untuk PKL makanan siap saji yang memiliki tenda, biasanya menyiapkan ruang lesehan bagi pembeli yang ingin makan di tempat. Pengunjung yang makan ditempat akan membutuhkan tempat untuk memarkirkan kendaraannya. Temuan ini sesuai dengan Novelia [8] yang menyatakan bahwa lokasi PKL seringkali mendekati lokasi tempat parkir.

Tabel 6. Hasil skoring variabel luas ruang PKL.

\begin{tabular}{lllllllll}
\hline \multicolumn{8}{c}{ Urutan 2 - Luas Ruang PKL } \\
(Indeks Persentase: 84,77\%)
\end{tabular}

3.2.3 Preferensi PKL terhadap pusat aktivitas. Berdasarkan hasil analisis preferensi PKL, pusat aktivitas menempati urutan ketiga dari tujuh karakteristik yang paling dipertimbangkan PKL dalam memilih lokasi berdagang. Pusat aktivitas adalah pusat-pusat kegiatan yang berada terdekat dengan PKL dalam jarak jangkauan pelayanan PKL yakni $3 \mathrm{Km}$ (Hanarti dalam Haryanti, [16]). Pusat-pusat aktivitas yang terdapat di sekitar kawasan antara lain Taman Cerdas, Kantor Kecamatan Jebres, Kantor Kementrian Agraria Dan Tata Ruang atau BPN, Kampus ISI dan UNS, Balai Diklat Industri, serta Solo Techno Park yang merupakan pusat aktivitas pendidikan dan perkantoran, sehingga sesuai dengan Kadir [9] yang 
menyatakan PKL memilih lokasi dengan karakteristik penggunaan ruang yang memiliki berbagai jenis pusat kegiatan atau terdapat mixed use area.

Pendapat ini juga didukung oleh Widjajanti [13] yang mengemukakan bahwa keberadaan PKL biasanya memilih lokasi yang dekat dengan kompleks aktivitas pendidikan dan aktivitas lainnya seperti perdagangan, perkantoran, maupun perumahan. Selain dikelilingi pusat aktivitas pendidikan dan perdagangan, terdapat pula kawasan perumahan warga atau permukiman pelajar yang berada tidak jauh dari Kawasan Solo Techno Park. Hal ini dianggap menguntungkan bagi PKL sehingga pusat aktivitas dapat dianggap hal penting dalam penentuan lokasi seperti yang tertera pada Tabel 7. Terutama bagi PKL makanan siap saji yang sebagian besar menempati lokasi kawasan Solo Techno Park, para pedagang cenderung memilih berlokasi mendekati fungsi perdagangan dan perkantoran [15].

Sebagian besar pusat aktivitas secara formal beroperasi sejak pukul 08.00 hingga tutup pukul 17.00. PKL di Kawasan Solo Techno Park lebih aktif pada malam hari meskipun pada malam hari pusat-pusat aktivitas ini tutup, karena terdapat peraturan daerah yang membatasi jam buka dan tutup bagi PKL yakni dari pukul 17.00 hingga 05.00. Hal ini sesuai dengan fakta di lapangan bahwa sebagian besar PKL di Kawasan Solo Techno Park mulai beroperasi pada malam hari, dan tidak berjualan pada siang hari, dan sebagian kecil lainnya pindah lokasi berjualan saat siang hari ke lokasi lain yang dekat dari Kawasan Solo Techno Park yaitu di Jalan Surya dan depan Asgros Ngoresan hingga yang cukup jauh yakni di UMS Sukoharjo, USB Mojosongo, dan sebagian berjualan di rumah. PKL di Kawasan Solo Techno Park didominasi oleh PKL makanan siap saji yang sebagian besar menetap (static) dan juga ada pula yang berpindah (semi-static). Untuk dapat mengakomodasi berbagai sifat pelayanan PKL, dalam melakukan relokasi PKL sebaiknya pemerintah memilih lokasi yang dekat dengan berbagai pusat aktivitas, serta di kawasan yang memungkinkan PKL untuk berjualan 24 jam.

Tabel 7. Hasil skoring variabel pusat aktivitas.

\begin{tabular}{|c|c|c|c|c|c|c|}
\hline \multicolumn{7}{|c|}{ Urutan 3 - Pusat Aktivitas (Indeks Persentase: 82,92\% ) } \\
\hline Kode & Item Pernyataan & STS & TS & $\mathbf{N}$ & $\mathbf{S}$ & SS \\
\hline pa1 & $\begin{array}{l}\text { Saya berjualan di lokasi Kawasan Solo } \\
\text { Techno Park karena dekat dengan } \\
\text { berbagai pusat aktivitas seperti kampus } \\
\text { UNS dan ISI, Solo Techno Park, Gedung } \\
\text { Diklat, Kantor Kecamatan, dsb }\end{array}$ & $0 \%$ & $3,08 \%$ & $12,31 \%$ & $43,08 \%$ & $41,54 \%$ \\
\hline pa2 & $\begin{array}{l}\text { Saya merasakan keuntungan maupun } \\
\text { manfaat berjualan didekat tempat-tempat } \\
\text { tersebut meskipun berjualan pada waktu } \\
\text { tempat-tempat tersebut tutup/tidak ada } \\
\text { aktivitas }\end{array}$ & $0 \%$ & $6,15 \%$ & $6,15 \%$ & $63,08 \%$ & $24,62 \%$ \\
\hline
\end{tabular}

3.2.4 Preferensi PKL terhadap aksesibilitas. Berdasarkan hasil analisis preferensi PKL, aksesibilitas menempati urutan keempat dari tujuh karakteristik yang paling dipertimbangkan PKL dalam memilih lokasi berdagang. Kawasan Solo Techno Park terletak di 
Jalan Ki Hajar Dewantara yang digolongkan sebagai jalan lokal primer, yakni jalan yang menghubungkan secara berdaya guna pusat kegiatan nasional dengan pusat kegiatan lingkungan, pusat kegiatan wilayah dengan pusat kegiatan lingkungan, antarpusat kegiatan lokal, atau pusat kegiatan lokal dengan pusat kegiatan lingkungan, serta antarpusat kegiatan lingkungan [18]. Kawasan Solo Techno Park terletak di jalan arteri primer yang ramai dilalui masyarakat luas menjadi alasan PKL memilih lokasi dibanding lokasi lainnya yang lebih dekat dari tempat tinggal. Hal ini sesuai dengan pendapat Kadir [9] bahwa PKL mempertimbangkan letak di lokasi yang memiliki kemudahan aksesibilitas dengan jalan yang baik, menempati area di pinggir jalan dan trotoar karena lebih mudah menjajakan dagangannya sesuai dengan Tabel 8. Sastrawan [10] menyebutkan lokasi yang dipilih PKL adalah jalan yang dilalui atau mudah di jangkau sarana transportasi umum. Hal ini kurang sesuai dengan keadaan di Kawasan Solo Techno Park yang tidak dilalui jalur angkutan umum. Meskipun tidak dijangkau sarana transportasi umum, kawasan tetap ramai karena pengunjung yang datang adalah pejalan kaki/pedestrian serta pengguna jalan yang menggunakan kendaraan pribadi.

Tabel 8. Hasil skoring variabel aksesibilitas PKL.

\begin{tabular}{lllllllc}
\hline \multicolumn{7}{c}{$\begin{array}{l}\text { Urutan 4 - Aksesibilitas PKL } \\
\text { (Indeks Persentase: 82,62\%) }\end{array}$} \\
\hline Kode & Item Pernyataan & STS & TS & N & S & SS \\
\hline ak1 & $\begin{array}{l}\text { Lokasi PKL saya mudah untuk } \\
\text { diakses pengendara mobil maupun } \\
\text { motor }\end{array}$ & $0 \%$ & $0 \%$ & $26,15 \%$ & $43,08 \%$ & $30,77 \%$ \\
ak2 & $\begin{array}{l}\text { Banyak pengunjung yang datang } \\
\text { karena jalan tempat saya berlokasi } \\
\text { terhubung dengan ruas-ruas jalan } \\
\text { lainnya }\end{array}$ & & & & & \\
\end{tabular}

3.2.5 Preferensi PKL terhadap lalu lintas jalan. Berdasarkan hasil analisis preferensi PKL, lalu lintas jalan menempati urutan kelima dari tujuh karakteristik yang paling dipertimbangkan PKL dalam memilih lokasi berdagang sesuai dengan Tabel 9. Menurut Sastrawan [10] lalu lintas atau traffic menyangkut kepadatan dan kemacetan lalu lintas. Hal ini kurang sesuai dengan kondisi di lapangan, karena PKL di Kawasan Solo Techno Park menyatakan jarang melihat kemacetan di Jalan Ki Hajar Dewantara dan menilai hampir tidak pernah terjadi kemacetan. Jalan ini dilewati truk besar terutama saat malam hari, menjadikan jalan padat (tidak sampai macet) dan hal inipun jarang sekali terjadi, sehingga tidak memberi pengaruh apapun terhadap pembeli yang datang.

Meskipun demikian, Jalan Ki Hajar Dewantara tetap tergolong ramai karena volume kendaraan yang melewati jalan ini cukup besar setiap harinya terutama pada waktu-waktu tertentu. Pada situasi hari kerja (weekday), baik waktu pagi siang sore dan malam ruas jalan di Kawasan Solo Techno Park diketahui faktor ukuran kota (Fcs) arus stabil, tetapi kecepatan operasi mulai dibatasi oleh kondisi lalu lintas. Sedangkan pada situasi hari libur (weekend), faktor ukuran kota ruas jalan di Kawasan Solo Techno Park digolongkan dalam tingkat 
pelayanan B pada setiap waktu kecuali sore hari ketika kelas tingkat pelayanannya naik menjadi C, yang berarti arus stabil, tetapi kecepatan dan gerak kendaraan dikendalikan.

Tabel 9. Hasil skoring variabel lokasi strategis.

\begin{tabular}{lllllll}
\hline \multicolumn{7}{c}{$\begin{array}{l}\text { Urutan 5 - Lalu Lintas Jalan } \\
\text { (Indeks Persentase: 81,54\%) }\end{array}$} \\
\hline Kode & Item Pernyataan & STS & TS & N & S & SS \\
\hline II1 & $\begin{array}{l}\text { Saya berjualan di lokasi Kawasan } \\
\text { Solo Techno Park karena jalannya } \\
\text { ramai }\end{array}$ & $4,62 \%$ & $10,77 \%$ & $52,31 \%$ & $32,31 \%$ \\
II2 & $\begin{array}{l}\text { Saya merasa banyak orang datang } \\
\text { membeli karena kebetulan } \\
\text { melewati lokasinya berjualan }\end{array}$ & & & & \\
\end{tabular}

3.2.6 Preferensi PKL terhadap sarana dan prasarana PKL. Berdasarkan hasil analisis preferensi $P K L$, sarana dan prasarana PKL menempati urutan keenam dari tujuh karakteristik yang paling dipertimbangkan PKL dalam memilih lokasi berdagang. Duwit [11] menyatakan bahwa tersedianya utilitas penunjang kegiatan PKL di lokasi menjadi salah satu alasan PKL memilih lokasi. Hal ini kurang sesuai dengan fakta bahwa para PKL di Kawasan Solo Techno Park memiliki kecenderungan untuk membawa sarana berdagangnya dari rumah, namun tidak sedikit pula yang menitipkan sarananya di lokasi. Sebagian PKL di Kawasan Solo Techno Park menitipkan sarananya di sekitar lokasi, yakni kawasan Pedaringan. Menurut Maulidiyah dan Idajati [6], lokasi yang dipilih PKL dapat diketahui dari ketersediaan air bersih dan listrik di kawasan. Pernyataan ini juga kurang sesuai dengan keadaan PKL di Kawasan Solo Techno Park yang sama sekali tidak menggunakan prasarana kota. Prasarana yang dibutuhkan bagi sebagian PKL antara lain adalah listrik dan air. Listrik yang digunakan oleh PKL dipenuhi secara swadaya dengan bantuan aki dan powerbank. Sedangkan untuk kebutuhan air, seluruh PKL yang membutuhkan air membawa sendiri airnya dari rumah. Dapat disimpulkan bahwa PKL memenuhi seluruh kebutuhan sarana dan prasarananya sendiri (self-sufficient) seperti penjelasan pada Tabel 10.

Tabel 10. Hasil skoring variabel sarana prasarana PKL.

\begin{tabular}{lllllll}
\hline \multicolumn{7}{c}{$\begin{array}{c}\text { Urutan 6 - Variabel Sarana Prasarana PKL } \\
\text { (Indeks Persentase: 81,23\%) }\end{array}$} \\
\hline Kode & Item Pernyataan & STS & TS & N & S & SS \\
\hline sp1 & $\begin{array}{l}\text { Selama berjualan, kebutuhan listrik } \\
\text { ataupun air bersih saya selalu } \\
\text { terpenuhi dan tidak terkendala }\end{array}$ & $0 \%$ & $21,54 \%$ & $29,23 \%$ & $49,23 \%$ \\
sp2 & $\begin{array}{l}\text { Saya merasa nyaman untuk } \\
\text { menitipkan sarana berdagang } \\
\text { mereka di sekitar lokasi }\end{array}$ & & $7,69 \%$ & $13,85 \%$ & $64,62 \%$ & $13,85 \%$ \\
\hline
\end{tabular}


3.2.7 Preferensi PKL terhadap aglomerasi PKL. Berdasarkan hasil analisis preferensi PKL, aglomerasi PKL menempati urutan ketujuh dari tujuh karakteristik yang paling dipertimbangkan PKL dalam memilih lokasi berdagang. Aglomerasi adalah suatu pemusatan atau pengelompokkan pedagang sejenis atau pedagang yang mempunyai sifat komoditas yang sama atau saling menunjang. Menurut Budi [12] aglomerasi biasanya dijumpai pada para pedagang makanan dan minuman, sesuai dengan keadaan PKL di Kawasan Solo Techno Park yang cenderung lebih suka berkumpul dengan PKL lain dengan jenis dagangan yang sama yakni makanan siap saji. Disamping itu, terdapat dampak negatif dari aglomerasi yakni persaingan yang tinggi serta tidak sehat diantara para pedagang. PKL menyatakan bahwa berdagang dalam aglomerasi dapat menyebabkan pendapatan menurun jika banyak PKL lain yang berjualan jenis makanan yang sama. Hal ini sesuai dengan Sastrawan [10] yang berpendapat bahwa persaingan menjadi pertimbangan bagi PKL dalam menentukan lokasi sesuai dengan penjelasan pada Tabel 11.

Tabel 11. Hasil skoring variabel aglomerasi PKL.

\begin{tabular}{llllllc}
\hline \multicolumn{7}{c}{$\begin{array}{c}\text { Urutan 7 - Variabel Aglomerasi PKL } \\
\text { (Indeks Persentase: 79,85\%) }\end{array}$} \\
\hline Kode & Item Pernyataan & STS & TS & N & S & SS \\
\hline ag1 & $\begin{array}{l}\text { Saya senang berjualan di Kawasan } \\
\text { Solo Techno Park karena banyak PKL }\end{array}$ & $4,62 \%$ & $12,31 \%$ & $58,46 \%$ & $24,62 \%$ \\
& $\begin{array}{l}\text { yang berjualan komoditas yang } \\
\text { sama dengan yang saya jual }\end{array}$ & & & & \\
ag2 & $\begin{array}{l}\text { Saya tidak merasa dirugikan dengan } \\
\text { persaingan antar PKL yang berjualan } \\
\text { komoditas yang sama dengan yang } \\
\text { saya jual }\end{array}$ & $9,23 \%$ & $10,77 \%$ & $55,38 \%$ & $24,62 \%$ \\
\end{tabular}

\section{Kesimpulan}

Kawasan Solo Techno Park sebagai lokasi berdagang sangat menarik bagi PKL yang menempatinya. Preferensi PKL dalam menentukan sebuah lokasi sangat berhubungan erat dengan karakteristik yang dimiliki oleh PKL. Karakteristik aktivitas PKL menjadi pertimbangan penting PKL dalam menentukan lokasi yang cocok untuk melakukan aktivitas perdagangan. Hasil kompilasi data serta analisis juga menunjukkan karakteristik PKL yang berjualan di Kawasan Solo Techno Park sangat cocok dengan karakteristik lokasi yang ada di kawasan, sehingga meskipun sudah berulang kali dilakukan penataan, PKL tetap kembali lagi. Keadaan ini akan terus berlanjut hingga lokasi baru yang memiliki karakteristik lokasi sesuai dengan karakteristik PKL serta preferensi PKL tersedia. Sehingga melakukan penataan, pemerintah perlu untuk mengenali karakteristik PKL dan preferensi berlokasinya, karena setiap kawasan PKL dapat memiliki karakter PKL dan preferensi karakter lokasi yang berbeda. Selain itu, dalam merencanakan tempat relokasi, kebutuhan konsumen menjadi sama pentingnya dengan kebutuhan PKL, sehingga hal tersebut perlu diperhatikan supaya program penataan PKL selanjutnya di masa yang akan datang dapat terlaksana secara lebih efektif dan efisien. 


\section{Referensi}

[1] Rachbini D J dan Abdul H 1994 Ekonomi Informal Perkotaan Gejala Involusi Gelombang Kedua (Jakarta: LP3ES)

[2] Walikota Surakarta 2012 Peraturan Walikota Surakarta No. 17-B Tahun 2012 tentang Petunjuk Pelaksanaan Peraturan Daerah No. 3 Tahun 2008 tentang Pengelolaan Pedagang Kaki Lima. Surakarta Diakses dari http://jdih.surakarta.go.id/jdihsolo/proses/produkhukum/file/5066PERWALI_NO_1 7-B_TAHUN_2012.pdf

[3] McGee T G dan Yue-Man Y 1977 Hawkers in Southeast Asian Cities: Planning For The Bazaar Economy (Ottawa: International Development Research Centre)

[4] Riduwan 2013 Metode dan Teknik Menyusun Tesis (Bandung: Alfabeta)

[5] Salvatore D 1997 Ekonomi Internasional (Jakarta: Penerbit Erlangga)

[6] Maulidiyah F D A dan Hertiari I 2016 Faktor yang Mempengaruhi Kriteria Lokasi Berdagang Pedagang Kaki Lima Berdasarkan Preferensi Pedagang Kaki Lima di Kawasan Pasar Baru Gresik Jurnal Teknik ITS 52 pp C145-C150 DOI: 10.12962/j23373539.v5i2.18564

[7] Widodo A 2000 Faktor-Faktor yang Mempengaruhi Pemilihan Lokasi Usaha Pedagang Kaki Lima (Studi Kasus: Kota Semarang) Masters Tesis Program Magister Perencanaan Pembangunan Wilayah dan Kota (Semarang: UNDIP) Diakses dari http://eprints.undip.ac.id/14439/1/2000MTPK604.pdf

[8] Novelia A S dan Sardjito 2015 Kriteria Penentuan Lokasi Pedagang Kaki Lima berdasarkan Preferensi Pedagangnya di Kawasan Perkotaan Sidoarjo Jurnal Teknik ITS 41 pp C28-C32 DOI: 10.12962/j23373539.v4i1.8981

[9] Kadir I 2010 Studi Karakteristik Penggunaan Ruang Pedagang Kaki Lima (PKL) di Kawasan Eks Pasar Lawata (Studi Kasus: Jalan Taman Surapati Kota Kendari) $\begin{array}{lllllll}\text { Metropilar } & 8 & 1 & \text { pp } & 108-16 & \text { Diakses }\end{array}$ http://118.97.35.230/pustaka/download/ishakkadir/STUDI\%20KARAKTERISTIK\%20PENGGUNAAN\%20RUANG\%20PEDAGANG\%20K AKI\%20LIMA\%20(PKL).pdf

[10] Sastrawan I W 2015 Analisis Faktor-Faktor Yang Mempengaruhi Pemilihan Lokasi Usaha Pedagang Kaki Lima di Pantai Penimbangan Kecamatan Buleleng, Kabupaten Buleleng. Jurnal Pendidikan Ekonomi Universitas Pendidikan Ganesha 51 DOI: 10.23887/jjpe.v5i1.5084

[11] Duwit B S, Kumurur V A dan Moniaga I L 2015 Persepsi Pedagang Kaki Lima Terhadap Area Berjualan Sepanjang Pasar Pinasungkulan Karombasan Manado Sabua: Jurnal Lingkungan Binaan dan Arsitektur 72 pp 419 - 27 Diakses dari https://ejournal.unsrat.ac.id/index.php/SABUA/article/view/9586

[12] Budi A S 2006 Kajian Lokasi Pedagang Kaki lima Berdasarkan Preferensi PKL Serta Persepsi Masyararakat Sekitar Di Kota Pemalang. Diakses dari http://eprints.undip.ac.id/16503/1/ARI_SULISTIYO_BUDI.pdf

[13] Widjajanti R 2012 Karakteristik Aktivitas Pedagang Kaki Lima di Ruang Kota (Studi Kasus: Kawasan Pendidikan Tembalang, Kota Semarang) Jurnal Pembangunan Wilayah dan Kota 84 pp 412-24 DOI: 10.14710/pwk.v8i4.6498 
[14] Rahayu M J et al 2014 Peran PKL Dalam Proses Penataan Berbasis Partisipatif di Kota Surakarta Architecture Event 2014: Membangun Karakter Kota Berbasis Lokalitas (Surakarta: Jurusan Arsitektur Universitas Sebelas Maret)

[15] Rahayu M J dan Wulandari R 2016 Hubungan Karakter Aktivitas dan Karakter Berlokasi PKL di Kota Surakarta Jurnal Pembangunan Wilayah dan Perencanaan Partisipatif REGION 71 pp 1-10 DOI: 10.20961/region.v7i1.5774

[16] Haryanti D T 2008 Kajian Pola Pemanfaatan Ruang Terbuka Publik Kawasan Bundaran Simpang Lima Semarang Tesis Program Magister Teknik Perencanaan Wilayah dan Kota (Semarang: UNDIP) Diakses dari http://eprints.undip.ac.id/17085/1/DINI_TRI_HARYANTI.pdf

[17] Widjajanti R 2012 Karakteristik Aktivitas Pedagang Kaki Lima pada Kawasan Komersial di Pusat Kota Studi Kasus: Simpang Lima, Semarang TEKNIK 30 pp 162-70 DOI: 10.14710/teknik.v30i3.1892.

[18] Peraturan Pemerintah No. 34 Tahun 2006 tentang Jalan Diakses dari https://pelayanan.jakarta.go.id/download/regulasi/peraturan-pemerintah-nomor34-tahun-2006-tentang-jalan.pdf 